Effectiveness of Education in Improving Medical Emergency Team (MET)

Nurses' Performance

\title{
A Systematic Literature Review
}

\section{Sinikka Leppänen* RN, BHSc}

University of Oulu, Finland, Raivaajantie 32, FI-90140 Oulu, Finland, sinikka.leppanen58@gmail.com

Miia Jansson, PhD, RN, Postdoctoral researcher

Medical Research Center Oulu, Oulu, Finland, Tuuliviirintie 4a2 FI-90540 Oulu, Finland miia.jansson@,oulu.fi,

Hanna-Mari Pesonen PhD, RN, Postdoctoral researcher

Research Unit of Nursing Science and Health Management, P.O.Box 5000, FI-90014, University of Oulu, Finland, hanna-mari.pesonen@oulu.fi

\section{Satu Elo, PhD, Adjunct professor, consultant}

Research Unit of Nursing Science and Health Management, P.O.Box 5000, 90014 University of Oulu, Finland, Oulu University Hospital, satu.elo@oulu.fi

*Corresponding author: sinikka.leppanen58@gmail.com (Sinikka Leppänen) 


\section{Abstract}

2 Background:

3 The National Safety Goal recommendation for American hospitals, the Australian Commission on 4 Safety and Quality in Health Care and The European Resuscitation Council Guidelines for

5 Resuscitation recommend the use of a Medical Emergency Team (MET) - system to improve hospital 6 safety and quality of care through preventing cardiac arrests and unplanned ICU admissions. 7 However, there is little evidence of its effectiveness.

8 Objective:

9 To evaluate the effectiveness of educational interventions in improving MET nurses' performance.

10 Methods:

11 The systematic literature review was conducted in five multi-disciplinary databases without any time constraint during the autumn 2016. The studies were selected and assessed by two researches independently. The analysis was conducted by following the principals of narrative synthesis.

\section{Results:}

Due to a lack of suitable studies only two studies were included in the review. They confirmed simulation team training to be effective and preferred method amongst MET team. Specific role assumption and tasks completion increased MET effectiveness.

\section{Conclusion:}

The effectiveness of MET educational interventions remains unclear due to the lack of published studies. There is a need for new innovative educational intervention studies to clarify, educate, evaluate and improve MET nurses' performance and their assigned tasks and roles.

\section{Keywords}

Medical Emergency Team (MET); Rapid Response Team (RRT); MET nurse; Education; Training

\section{Key Points:}

1. Simulation provides opportunities for team training, and simulation is a recognized MET training tool.

2. The most effective educational interventions for MET are still questionable. As ICU nurses are frequent members in MET, their effective education can influence the whole team performance as well as the hospital safety and quality.

3. Randomized controlled trial studies are needed to evaluate the effectiveness of different kinds of simulation-based interventions as well as to compare them to other educations to determine the most effective education for the MET system.

\section{Highlights:}

- The effectiveness of education on MET nurses' performance remains unclear.

- Simulation education is preferred method for MET.

- Efficiency improves by assuming specific roles and performing role delineated tasks.

- New educational intervention studies are needed to evaluate MET performance. 


\section{Background}

The National Safety Goal recommendation for American hospitals (Winters \& DeVita, 2011), the Australian Commission on Safety and Quality in Health Care (2014) consultation report and The European Resuscitation Council Guidelines for Resuscitation in 2015 (Soar et al., 2015) recommend the use of a Medical Emergency Team (MET) - also known as Rapid Response Team (RRT) - system to improve hospital safety and quality of care (Peberdy et al., 2007). In this paper, however, the term MET is used either meaning RRT or MET.

The purpose of MET system is to detect and response to deteriorating hospital ward patients to prevent cardiac arrests and unplanned ICU admissions (White, Scott, Vaux, \& Sullivan, 2015; Soar et al., 2015). MET systems also emphasize the importance of educating in early detection (Winters \& DeVita, 2011). Even though the MET system has been in place in many hospitals, there is little evidence of its effectiveness (White et al., 2015).

\section{Education of MET}

Simulation-based education has been recognized as a MET training tool (Sakai \& DeVita, 2009; Frengley et al., 2011), which has strong educational effects specifically on participants' psychomotor skills (Kim, Park, \& Shin, 2016), in improving nurses' skills in recognition and treatment of instability (Hravnak, Beach, \& Tuite, 2007), and refining team skills (Wallin, Meurling, Hedman, Hedegård, \& Felländer-Tsai, 2007; Niell et al., 2015). Moreover, high fidelity simulation education has been superior to traditional methods of teaching in enhancing resuscitation teams' communication, teamwork and leadership skills (Murphy, Curtis, \& McCloughen, 2015; Warren, Luctkar-Flude, Godfrey, \& Lukewich, 2016) by increasing participants' knowledge, confidence, and satisfaction (Warren et al., 2016). However, the effectiveness of simulation education in intensive care unit (ICU) nurses’ continuing education is lacking (Jansson, Kääriäinen, \& Kyngäs, 2013).

As ICU nurses (Jones,Drennan, Hart, Bellomo, \& Steven, 2012; Tirkkonen, Nurmi, Olkkola, Tenhunen, \& Hoppu, 2014) are regular members in METs and these teams respond annually to hundreds of MET calls (Tirkkonen, Tamminen, \& Skrifvars, 2017), the skills and attitudes of MET nurses can make an impact during the MET event (Jones, King, \& Wilson, 2009). In some MET systems ICU based MET nurse can be alone the first responder (Tirkkonen et al., 2014; Winters \& DeVita, 2011). During a MET call MET nurses spend almost half of their time assessing the patient and re-evaluating their risks, therefore, MET nurse education should support these roles (Santiano et al., 2011). Met nurses' assessment and team leadership skill as well as their work attitude play an 
important role in the effectiveness of MET - event (Topple et al., 2016a). However, the effectiveness of MET education involving ICU nurses being part of the MET team is unknown.

Therefore, the aim of the present study was to evaluate MET educational interventions involving ICU nurses as team members by performing a systematic literature review. The main question addressed in the study was "What is the effectiveness of MET educational interventions in improving the knowledge and skills of ICU based nurses while responding to MET calls?” Only intervention studies were included in this systematic literature review.

\section{Material and Methods}

\section{$81 \quad$ Search Strategy and Limitations}

82 This systematic literature review was conducted by the following study process guidelines from Centre for Reviews and Dissemination (Center for Reviews and Dissemination, 2009) and Joanna Briggs Institute User guide (Joanne Briggs Institute, 2014). The data was collected from five different databases in December 2016. Initially 338 studies were found from different databases as follows: Scopus $(n=117)$, Web of Science $(n=53)$, CINAHL $(n=60)$, ProQuest $(n=98)$ and Medic $(n=10)$. Duplicates $(\mathrm{n}=154)$ were removed to reduce publication bias (Center for Reviews and Dissemination, 2009). The final number of studies for the selection process formed to be 184 (Table 1).

The library information specialist was consulted to determine suitable databases, search strategies, terms and limitations (Aromataris \& Riitano, 2014). Search terms of the databases explained in Table left open. The search strategy was carefully documented and original searches maintained in the Webbased research management tool RefWorks (Higgins \& Green, 2011).

Table 1. Search strategy, terms, limitations and number of studies

\begin{tabular}{|c|c|c|}
\hline Database & Search terms (Article title, abstract, keywords) & $\mathbf{N}$ \\
\hline Scobus & $\begin{array}{l}\text { "Medical Emergency" OR "Rapid Response" OR "Critical Care Outreach" OR } \\
\text { "Patient at Risk" AND team* AND competenc* OR skill* OR training* OR education* } \\
\text { OR capabilit* AND nurs* }\end{array}$ & 116 \\
\hline $\begin{array}{l}\text { Web of } \\
\text { Science }\end{array}$ & $\begin{array}{l}\text { "Medical Emergency" OR "Rapid Response" OR "Critical Care Outreach" OR "Patient } \\
\text { at Risk" AND team* AND competenc* OR skill* OR training* OR education* OR } \\
\text { capabilit* AND nurs* }\end{array}$ & 17 \\
\hline Proquest & $\begin{array}{l}\text { "Medical Emergency" OR "Rapid Response" OR "Critical Care Outreach" OR "Patient } \\
\text { at Risk" AND team* AND competenc* OR skill* OR training* OR education* OR } \\
\text { capabilit* AND nurs* }\end{array}$ & 15 \\
\hline Cinahl & $\begin{array}{l}\text { "Medical Emergency" OR "Rapid Response" OR "Critical Care Outreach" OR "Patient } \\
\text { at Risk" AND team* AND competenc* OR skill* OR training* OR education* OR } \\
\text { capabilit* }\end{array}$ & 26 \\
\hline Medic & $\begin{array}{l}\text { "Medical Emergency" OR "Rapid Response" OR "Critical Care Outreach" OR "Patient } \\
\text { at Risk" AND team }\end{array}$ & 10 \\
\hline \multicolumn{2}{|c|}{ Total number of studies for the selection process } & 184 \\
\hline
\end{tabular}




\section{Inclusion Criteria, Study Selection and Quality Appraisal}

96 The following inclusion criteria were adopted from PICoS (Center for Reviews and Dissemination, 2009) for this review: $\mathrm{P}=$ participants (ICU Registered Nurse members of MET or equivalent team of adult somatic hospital environment), $\mathrm{I}=$ phenomena of interest (Education intervention), $\mathrm{C}=$ context (none), $\mathrm{O}=$ outcome (Learning outcomes), $\mathrm{S}=$ types of studies (Peer reviewed, original study, published in English or Finnish, publishing year open). The exclusion criteria of participants ruled out conducted researches of students, ward nurses, medical officers, other emergency team members, MET originating from other units than ICU, MET for other than adult somatic wards: Paediatrics, psychiatry, Obstetrics, Operation Room, Trauma, Emergency Department, Dental and Resuscitation Team study merely of CPR training. The 184 selected studies for this review were screened in a three-phase selection process. Screening phases were: titles $(n=184)$, abstracts $(n=48)$ and full text (14). This process was carried out by two researchers (SL, MJ) independently and objectively (Center for Reviews and Dissemination, 2009).

108 Figure one clarifies the PRISMA study-selection and exclusion process. Researchers' disagreements regarding study eligibility were resolved through discussion. During the full text screening phase an e-mail was send to one author of the selected study (Frengley et al., 2011) to question whether their study population included MET personal. This study was excluded due to unsuitable population. Due to a minimal study result $(\mathrm{n}=2)$ one researcher (SL) additionally screened the references of all the selected full text articles $(n=14)$. The total number of references screened from these articles was

114368 , twenty abstracts and two full texts were read. This extra screening did not increase the literature 115 search result.

116 Finally, the two researchers independently assessed the methodological quality of the relevant studies 117 using the JBI MAStARI critical appraisal tool for descriptive studies (Joanne Briggs Institute, 2014). 118 The quality was calculated by the reviewers (SL, MJ) assigning scores 0 or 1 for each suitable 119 checklist question, maximum possible score was $5 / 5$. The included studies received $3-4 / 5$, being 120 more than $50 \%$ of the total possible score. There was a common consensus between the reviewers 121 regarding the quality scores. 
123

124

125

130

131

136

137

138

139

143
144
145
146
147

154

156

162
163

\section{Search Result total $(n=338)$}

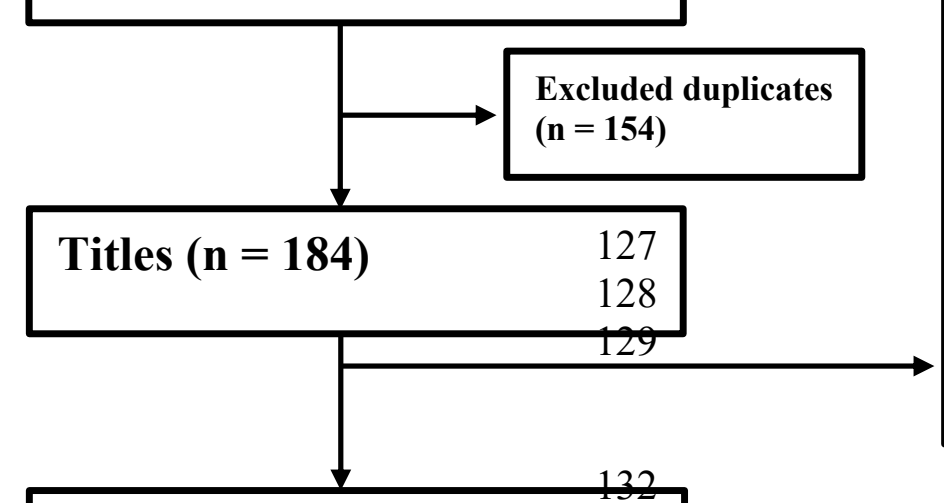

Excluded Studies (n=136)

Population:

Dental research $(\mathrm{n}=1)$

Military research $(\mathrm{n}=1)$

Obstetrics research $(\mathrm{n}=1)$

Occupational therapist research $(\mathrm{n}=1)$

Paediatric research $(\mathrm{n}=5)$

Pharmacy research $(\mathrm{n}=2)$

Psychiatry research $(\mathrm{n}=2)$

Trauma team research $(\mathrm{n}=1)$

Undergraduate research $(\mathrm{n}=6)$

Ward nurse research $(\mathrm{n}=1)$

Not medical field research $(n=4)$ Intervention:

Not educational intervention $(\mathrm{n}=111)$

\section{Excluded Studies $(n=34)$}

Population:

Medical Officers ( $\mathrm{n}=1)$

Other team; Radiology $(\mathrm{n}=1)$

Undergraduate research $(\mathrm{n}=1)$

Ward nurse research $(n=8)$

Intervention:

Not educational intervention $(\mathrm{n}=23)$

\section{Excluded Studies $(n=12)$}

Population:

Medical Officers ( $\mathrm{n}=1$ )

Other teams $(\mathrm{n}=3)$ : Not a clear MET team, ICU team,

Resuscitation team

Ward nurse $(\mathrm{n}=5)$

Undergraduate $(\mathrm{n}=1)$

Intervention:

Not educational intervention $(\mathrm{n}=2)$

\section{Included studies $(\mathrm{n}=2)$}

Figure 1. Flowchart of the study-selection proce $\begin{array}{r}164 \\ 165\end{array}$

\section{Data Extraction and Analysis}

The research material from the included study articles was processed (Center for Reviews and Dissemination, 2009), and an extraction table was created (Table 2) by following instructions from Higgins and Green (2011) and Centre for Review and Dissemination (2009). This data extraction table was designed to answer the specific review questions (Center for Reviews and Dissemination, 2009) and objectives (Joanne Briggs Institute, 2014) to attain all the necessary information from the 
174 included studies. The data extraction and analysis was conducted by one researcher (SL) and 175 confirmed by the other researcher $(\mathrm{MJ})$ to minimize bias and errors in the data extraction process 176 (Center for Reviews and Dissemination, 2009; Polit \& Beck, 2012).

177 The summarized findings of the included studies were created by using the principles of narrative 178 synthesis (Munn, Tufanaru, \& Aromataris, 2014). The indexes of the inter-rater reliability (Polit \& 179 Beck, 2012) were not calculated due to the complete agreement achieved by the two researchers 180 regarding the final selection. 
Table 2. Study characteristics of included original studies

\begin{tabular}{|c|c|c|c|c|}
\hline $\begin{array}{l}\text { Study, } \\
\text { Country }\end{array}$ & $\begin{array}{l}\text { Setting, } \\
\text { Participants }\end{array}$ & Intervention & $\begin{array}{l}\text { Outcome } \\
\text { Measurements }\end{array}$ & Results \\
\hline $\begin{array}{l}\text { Devita et } \\
\text { al., } \\
\text { 2005 } \\
\text { USA }\end{array}$ & $\begin{array}{l}\text { Setting: } \\
\text { The University of } \\
\text { Pittsburgh Medical } \\
\text { Center Winter } \\
\text { Institute for } \\
\text { Simulation Education } \\
\text { and Research } \\
\text { Participants: } \\
69 \text { critical care } \\
\text { nurses, } \\
48 \text { physicians, and } \\
21 \text { respiratory } \\
\text { therapists } \\
\text { (n=138). } \\
\text { 8 Team members: } \\
2 \text { ICU nurses, } 1 \text { ward } \\
\text { nurses, } 1 \text { Respiratory } \\
\text { therapist, and } 3 \text { - } 4 \\
\text { physicians, maybe } \\
\text { one student }\end{array}$ & $\begin{array}{l}\text { 10 one day courses, } \\
\text { each had } 4 \text { parts: } \\
\text { 1. A web based } \\
\text { presentation and } \\
\text { pre-test before the } \\
\text { course; The pre- } \\
\text { test covering the } \\
\text { web based } \\
\text { curriculum. } \\
\text { 2. A brief reinforcing } \\
\text { didactic session on } \\
\text { the day of the } \\
\text { course } \\
\text { 3. Three of five } \\
\text { different simulated } \\
\text { scenarios, each } \\
\text { followed by } \\
\text { 4. Debriefing and } \\
\text { analysis with the } \\
\text { team. Scenario } \\
\text { was random. } \\
\text { In scenarios } \\
\text { predetermined roles } \\
\text { were assumed. }\end{array}$ & $\begin{array}{l}\text { Primary outcome: } \\
\text { Successful crisis } \\
\text { management results in } \\
\text { SimMan "survival" } \\
\text { Secondary outcomes: } \\
\text { Completion of } \\
\text { organizational and } \\
\text { patient care tasks } \\
\text { Evaluations of: } \\
\text { 1. specific role } \\
\text { assumption } \\
\text { 2. tasks completion } \\
\text { those associated } \\
\text { with the role } \\
\text { 3. co-operation } \\
\text { The team's } \\
\text { performance rated by } \\
\text { the team and the } \\
\text { facilitator. } \\
\text { Objective measure: } \\
\text { specific task } \\
\text { completion. }\end{array}$ & $\begin{array}{l}\text { SimMan "survival" } \\
\text { improved from } 0 \% \text { to } \\
90 \% \text { during } 3 \text { sessions } \\
\text { in a day's course. } \\
\text { TCR improved from } \\
31 \% \text { to } 89 \% \text {, and each } \\
\text { simulator role improved } \\
\text { from } 10-45 \% \text { during } \\
\text { the first session, } 80- \\
95 \% \text { during the third } \\
\text { session. } \\
\text { TCR improved between } \\
\text { both the } 1 \text { st and } 2 \text { nd } \\
\text { sessions }(\mathrm{p}=0.002) \text { and } \\
\text { between the } 2 \text { nd and 3rd } \\
\text { sessions }(\mathrm{p}=0.011) \text {. }\end{array}$ \\
\hline $\begin{array}{l}\text { Paul } \\
\& \\
\text { Lane } \\
2014 \\
\text { USA }\end{array}$ & $\begin{array}{l}\text { Setting: } \\
\text { St. Mary Corwin } \\
\text { Medical Center } \\
\text { together with Pueblo } \\
\text { Community College } \\
\text { Participants: } \\
\text { All staff, who either } \\
\text { call MET or respond } \\
\text { to the call; } 12 \\
\text { resident physicians } \\
\text { and } 158 \text { nurses ( } 23 \\
\text { from ICU and rest } \\
\text { from various units } \\
\text { around hospital). } \\
\text { 6 Team members: } \\
1 \text { ICU nurse, } 3 \text { ward } \\
\text { nurses, } 1 \text { ED nurse, } \\
\text { and } 1 \text { physician. }\end{array}$ & $\begin{array}{l}\text { Simulation based team } \\
\text { training with Gaumard* } \\
\text { manikins } \\
56 \text { one hour courses, } \\
\text { debriefing time included } \\
\text { in one hour, } 8 \text { different } \\
\text { scenarios, which were } \\
\text { based on most common } \\
\text { MET calls. }\end{array}$ & $\begin{array}{l}\text { Performance } \\
\text { measured by criteria } \\
\text { evaluation form. } \\
\text { Additionally, anecdotal } \\
\text { notes taken by the } \\
\text { instructors during the } \\
\text { scenario. Participants } \\
\text { received informal and } \\
\text { formal feedback. } \\
\text { Survey sent to all } \\
\text { participants asking their } \\
\text { perception of the } \\
\text { training versus other } \\
\text { instructional methods. }\end{array}$ & $\begin{array}{l}\text { Debriefing findings: } \\
\text { Need for additional } \\
\text { training: } \\
\text { Communication; } \\
\text { assessment skills; } \\
\text { teamwork; critical } \\
\text { thinking; timely } \\
\text { initiation of MET calls; } \\
\text { cardiopulmonary and } \\
\text { resuscitation skill } \\
\text { retention. } \\
\text { Participants survey: } \\
\text { Response rate 52\% } \\
\text { Instructional method: } \\
\text { Very or somewhat } \\
\text { effective (91.4\%). } \\
\text { High-fidelity simulation } \\
\text { a preferred method } \\
\text { (63.6\%) versus case } \\
\text { studies, online learning } \\
\text { modules, or lecture. }\end{array}$ \\
\hline
\end{tabular}

Intensive Care Unit (ICU); Medical Emergency Team (MET); The task completion rate (TCR) 


\section{Results}

183 Due to lack of suitable studies only two original studies were included in this review (Table 2).

184 Included studies were prospective, quasi experimental intervention studies, conducted in single185 centres in the USA during 2005 and 2014. Both studies included ICU nurses as members of 186 multidisciplinary teams responding to medical crises in the form of METs.

\section{Course structures}

189 Both studies used a simulation-based education. The participants in the Paul and Lane (2014) study 190 included 23 ICU nurses, one of them taking part at the time in one hour training session. The DeVita 191 Schaefer, Lutz, Wang and Dongilli (2005) study included 69 critical care nurses of whom two had 192 specified roles and goals in each training session. These course structures are explained in table 2. 193 All scenario sessions in the DeVita et al. were video recorded to assist in debriefing, which focused 194 on reinforcing organizational aspects of team performance. Respectively, the criteria evaluation form 195 and The American Heart Association Debriefing methodology were utilized to guide the debriefing 196 sessions in the Paul and Lane study (2014).

\section{Effectiveness of the training}

198 In the study of DeVita et al. (2005), the manikin survival percentage change rate increased $90 \%$ across 199 the three sessions within the one day course $(p<0.002)$ in simulation environment. Most of the 200 improvements occurred between the first and the second sessions $(p<0.014)$ rather than between the 201 second and the third sessions $(\mathrm{p}<0.180)$. The overall mean improvement of the task completion rate 202 (TCR) percentage increased $58 \%(\mathrm{p}<0.001)$. The TCR was noticed to improve $47 \%$ between the 203 first and the second $(\mathrm{p}=0.002)$ and $11 \%$ between the second and the third sessions $(\mathrm{p}=0.011)$. In 204 addition, the performance of each of the role related tasks improved between sessions (DeVita et al., 205 2005).

206 In the study of Paul and Lane (2014), 92.1\% of respondents found that the simulated lab scenario 207 training to be very or somewhat effective. It was preferred by $63.6 \%$ of the trainees, when compared 208 to other methods. Most the participants stated that simulated sessions improved their critical thinking, 209 assessment skills, team work, understanding each person's role during a rapid response, and the importance of communication with the team. (Paul \& Lane, 2014.) 


\section{Discussion}

212 The main findings of this literature research were that the effectiveness of education on MET nurses'

213 performance remains unclear and that there is a need for future studies comparing the effectiveness 214 of different educational interventions to enhance patient safety and quality of care.

215 The study of DeVita et al. (2005) demonstrated significant advantages of simulation-based education 216 in quality of care and patient safety through improvements in manikin survival and TC rates during 217 simulated medical emergency response call -events. Respectively, majority of the respondents rated 218 the instructional methods effective and they preferred high-fidelity education rather than case studies, 219 online learning modules or classroom lectures (Paul \& Lane, 2014).

220 Included studies confirmed that MET simulation training for multidisciplinary hospital staff is 221 feasible and is the preferred training method when compared to other traditional methods. The 222 improvements regarding communication, critical thinking skills, collaboration and professionalism 223 (Paul \& Lane, 2014) were in line with other studies stating that simulation-based education improves 224 communication, teamwork and leadership and increases knowledge, confidence, and satisfaction 225 (Murphy et al., 2016; Warren et al., 2016).

226 Previous literature has demonstrated various effective simulation methods used in context of other 227 health care education when confronting and responding to emergency situations. These methods have 228 included simulated clinical scenarios (Jacobson et al., 2010), role-playing (Ertmer et al., 2010), mock 229 code simulations (Delac, Blazier, Daniel, \& N-Wilfong, 2013; Hill, Dickter, \& Van Daalen, 2010; 230 Herbers \& Heaser, 2016), e-learning (Ozekcin, Tuite, Willner, \& Hravnak, 2015), humanistic 231 simulation (Dwyer, Reid, McAllister, Guerin, \& Friel, 2015) and web-based programs (Liaw et al., 232 2016; Cooper et al., 2016) as an alternative to simulation methods. Recent meta-analysis of published, 233 controlled studies (1995 - 2013) suggests that simulation-based nursing educational interventions 234 have strong educational effects, especially in the psychomotor learning area. A variety of educational 235 interventions should be used to meet all the educational goals rather than press importance of fidelity 236 level of the used simulation. (Kim et al., 2016.)

237 Unfortunately, quasi experimental research designs without competing intervention or randomization 238 and pre- and post-measurements were used to measure the effectiveness of simulation education in 239 improving MET nurses' performance. The evaluations areas, covering knowledge; attitudes; skills 240 and satisfaction, should be measured preferably before and after training to provide tools for 241 evaluating used educational methods (Hardcastle, 2004; Warren et al., 2016; Guimond, Sole, \& Salas, 242 2011). In addition, there is a lack of published guidelines in describing the necessary skills and 243 training requirements for nurses participating in MET (Topple et al., 2016b). This, as well as the 244 variety of training methods and various team structures used, creates a challenge in comparing studies 
assessing MET nurses' skills, knowledge and the effectiveness of their education. The recently created and tested TEAM ${ }^{\mathrm{TM}}$ instrument could potentially be used as an assessment and or debriefing tool when measuring MET performance in training and clinical settings (Cant et al., 2016). Current literature involving MET education does not report the use of this validated instrument. This systematic review did not reveal any studies with research covering the retaining and transferring of the learned methods to the clinical environment. The Australian Commission on Safety and Quality in Health Care (2014) is currently mapping the skills, knowledge and behaviours required of all clinicians who are needed to recognise and respond to clinical deterioration. These mapping results will provide tools for future research and evaluation.

\section{Conclusion}

The effectiveness of MET educational interventions on ICU based nurses, regarding improving knowledge and skills required when responding to MET calls, remains unclear due to the lack of published studies. Both included studies confirmed that simulation team training is effective, feasible and even the preferred educational method amongst the practising MET members. There is clearly a need for new innovative educational intervention studies to clarify, educate, evaluate and improve the MET performance, team members' skill levels and their assigned tasks and roles.

\section{Limitations}

The search strategy included studies written in English and Finnish. This may have led to language bias (Center for Reviews and Dissemination, 2009). No publication limits were applied, which restricts publication bias (Joanne Briggs Institute, 2014). The results of this review clearly indicate that further research is needed to test MET educational interventions for their effectiveness.

The primary study search result was two original studies. The quality of the original studies was carefully assessed to ensure the validity of the review. Due to the minimal result, additional research was performed to cover as wide a scope of publication material as possible. The references of all selected full text articles were screened, but no more eligible studies were included.

\section{Implications for Research}

Further research is needed to outline effective educational interventions for MET as well as to measure team members' skills, knowledge, tasks and behaviours. Randomized controlled trial studies should be used to evaluate the effectiveness of different kinds of simulation-based interventions as well as compare them to other educational interventions to determine the most effective and suited 
278 education for the studied MET system. The quality and safety systems in each hospital setting vary 279 on a national and international level. This creates a challenge for MET related researches. Therefore, 280 universal research methods are required to standardize and unify this research area.

282 Acknowledgements

283 We would like to thank the library information specialist Sirpa Grekula from the Oulu University 284 Medical Library for her great assistance and guidance regarding the planning and accomplishing of 285 the study search. S.L, M.J, and S.E contributed to the study design. SL collected the data, SL and MJ 286 performed the selection process. SL analysed the data and drafted the manuscript. SE, MJ and HMP 287 made critical revisions to the paper for important intellectual content.

\section{Funding}

290 This research did not receive any specific grant from funding agencies in the public, commercial, or 291 not-for-profit sectors. 


\section{References}

Australian Commission on Safety and Quality in Health Care (ACSQHC). (2014). National Safety and Quality Health Service Standards: Training and competencies for recognising and responding to clinical deterioration TRIM D14-27589. Consultation report and options for action, November 2014. Accessed 29.3.17. Retrieved from https://www.safetyandquality.gov.au/wp-content/uploads/2014/11/Training-and-competenciesfor-recognising-and-responding-to-clinical-deterioration-Consultation-report-and-options-foraction-Nov-2014.pdf

Aromataris, E., \& Riitano, D. (2014). Constructing a search strategy and searching for evidence. American Journal of Nursing, 114(5), 49-56. doi:10.1097/01.NAJ.0000446779.99522.f6

Cant, R. P., Porter, J. E., Cooper, S. J., Roberts, K., Wilson, I., \& Gartside, C. (2016). Improving the non-technical skills of hospital medical emergency teams: The team emergency assessment measure (TEAM ${ }^{\mathrm{TM}}$ ). EMA - Emergency Medicine Australasia, 28(6), 641-646. doi:10.1111/1742-6723.12643

Cooper, S. J., Kinsman, L., Chung, C., Cant, R., Boyle, J., Bull, L., . . . Rotter, T. (2016). The impact of web-based and face-to-face simulation on patient deterioration and patient safety: Protocol for a multi-site multi-method design. 11. BMC Health Services Research, 16(1) doi:10.1186/s12913-016-1683-0

Center for Reviews and Dissemination (2009) Systematic reviews: CRD's quidance for undertaking reviews in health care. York, UK: York Publishing Services. ISBN 978-1900640473

Delac, K., Blazier, D., Daniel, L., \& N-Wilfong, D. (2013). Using mock code simulation to improve responder performance during the first 5 minutes of a code. Critical Care Nursing Quarterly, 36(2), 244-250. doi:10.1097/CNQ.0b013e3182846fla

DeVita, M. A., Schaefer, J., Lutz, J., Wang, H., \& Dongilli, T. (2005). Improving medical emergency team (MET) performance using a novel curriculum and a computerized human patient simulator. Quality and Safety in Health Care, 14(5), 326-331. doi:10.1136/qshc.2004.011148

Dwyer, T., Reid Searl, K., McAllister, M., Guerin, M., \& Friel, D. (2015). Advanced life simulation: High-fidelity simulation without the high technology. Nurse Education in Practice, 15(6), 430-436. doi:10.1016/j.nepr.2015.05.007

Ertmer, P. A., Strobel, J., Cheng, X., Chen, X., Kim, H., Olesova, L., . . Tomory, A. (2010). Expressions of critical thinking in role-playing simulations: Comparisons across roles. Journal of Computing in Higher Education, 22(2), 73-94. doi:10.1007/s12528-010-9030-7

Frengley, R. W., Weller, J. M., Torrie, J., Dzendrowskyj, P., Yee, B., Paul, A. M., .. . Henderson, K. M. (2011). The effect of a simulation-based training intervention on the performance of established critical care unit teams. Critical Care Medicine, 39(12), 2605-2611. doi:10.1097/CCM.0b013e3182282a98 
Guimond, M. E., Sole, M. L., \& Salas, E. (2011). Getting ready for simulation-based training: A checklist for nurse educators. Nursing Education Perspectives, 32(3), 179-185. doi:10.5480/1536-5026-32.3.179

Hardcastle, J. E. (2004). The meaning of effective education for critical care nursing practice: A thematic analysis. Australian Critical Care, 17(3), 114-122. doi:10.1016/S10367314(04)80013-4

Herbers, M. D., \& Heaser, J. A. (2016). Implementing an in situ mock code quality improvement program. American Journal of Critical Care, 25(5), 393-399. doi:10.4037/ajcc2016583

Higgins JPT \& Green S (editors) (2011) Cochrane Handbook for Systematic Reviews of Interventions Version 5.1.0 (updated March 2011). The Cochrane Collaboration, 2011. Available from www.handbook.cochrane.org. Cited 2016/11/21

Hill, C. R., Dickter, L., \& Van Daalen, E. M. (2010). A matter of life and death: The implementation of a mock code blue program in acute care. Medsurg Nursing : Official Journal of the Academy of Medical-Surgical Nurses, 19(5), 300-302, 304.

Hravnak, M., Beach, M., \& Tuite, P. (2007). Simulator technology as a tool for education in cardiac care. Journal of Cardiovascular Nursing, 22(1), 16-24.

Jacobson, T., Belcher, E., Sarr, B., Riutta, E., Ferrier, J. D., \& Botten, M. A. (2010). Clinical scenarios: Enhancing the skill set of the nurse as a vigilant guardian. Journal of Continuing Education in Nursing, 41(8), 347-353. doi:10.3928/00220124-20100503-06

Jansson, M., Kääriäinen, M., \& Kyngäs, H. (2013). Effectiveness of simulation-based education in critical care nurses' continuing education: A systematic review. Clinical Simulation in Nursing, 9(9), e355-e360. doi:10.1016/j.ecns.2012.07.003

Joanne Briggs Institute (2014) http://joannabriggs.org/assets/docs/sumari/reviewersmanual2014.pdf cited 2016/11/24.

Jones, D., Drennan, K., Hart, G. K., Bellomo, R., \& Steven, A. R. (2012). Rapid response team composition, resourcing and calling criteria in australia. Resuscitation, 83(5), 563-567. doi:10.1016/j.resuscitation.2011.10.023

Jones, L., King, L., \& Wilson, C. (2009). A literature review: Factors that impact on nurses' effective use of the medical emergency team (MET). Journal of Clinical Nursing, 18(24), 3379-3390. doi:10.1111/j.1365-2702.2009.02944.x

Kim, J., Park, J. -H., \& Shin, S. (2016). Effectiveness of simulation-based nursing education depending on fidelity: A meta analysis. BMC Medical Education, 16(1) doi:10.1186/s12909016-0672-7

Liaw, S. Y., Wong, L. F., Ang, S. B. L., Ho, J. T. Y., Siau, C., \& Ang, E. N. K. (2016). Strengthening the afferent limb of rapid response systems: An educational intervention using web-based learning for early recognition and responding to deteriorating patients. BMJ Quality and Safety, 25(6), 448-456. doi:10.1136/bmjqs-2015-004073 
Murphy, M., Curtis, K., \& McCloughen, A. (2016). What is the impact of multidisciplinary team simulation training on team performance and efficiency of patient care? an integrative review. Australasian Emergency Nursing Journal, 19(1), 44-53. doi:10.1016/j.aenj.2015.10.001

Munn, Z., Tufanaru, C., \& Aromataris, E. (2014). Data extraction and synthesis. American Journal of Nursing, 114(7), 49-54. doi:10.1097/01.NAJ.0000451683.66447.89

Niell, B. L., Kattapuram, T., Halpern, E. F., Salazar, G. M., Penzias, A., Bonk, S. S., . . Gordon, J. A. (2015). Prospective analysis of an interprofessional team training program using highfidelity simulation of contrast reactions. American Journal of Roentgenology, 204(6), W670W676. doi:10.2214/AJR.14.13778

Ozekcin, L. R., Tuite, P., Willner, K., \& Hravnak, M. (2015). Simulation education: Early identification of patient physiologic deterioration by acute care nurses. Clinical Nurse Specialist, 29(3), 166-173. doi:10.1097/NUR.0000000000000123

Paul, G., \& Lane, E. (2014). Inside the debriefing room: Multidisciplinary rapid response team training findings revealed. Clinical Simulation in Nursing, 10(5), e227-e233. doi:10.1016/j.ecns.2013.09.005

Peberdy, M. A., Cretikos, M., Abella, B. S., DeVita, M., Goldhill, D., Kloeck, W., . . Young, L. (2007). Recommended guidelines for monitoring, reporting, and conducting research on medical emergency team, outreach, and rapid response systems: An utstein-style scientific statement - A scientific statement from the international liaison committee on resuscitation (american heart association, australian resuscitation council, european resuscitation council, heart and stroke foundation of canada... Circulation, 116(21), 2481-2500. doi:10.1161/CIRCULATIONAHA.107.186227

Polit, D., \& Beck C. (2012). Nursing Research. Generating and Assessing Evidence for Nursing Practice. (9th ed.). Philadelphia; Wolters Kluwer Health/Lippincott Williams \& Wilkins. 94 125.

Sakai, T., \& DeVita, M. A. (2009). Rapid response system. Journal of Anesthesia, 23(3), 403-408. doi:10.1007/s00540-009-0778-8

Santiano, N., Young, L., Baramy, L. S., Cabrera, R., May, E., Wegener, R., . . Whelan, M. (2011). The impact of the medical emergency team on the resuscitation practice of critical care nurses. BMJ Quality and Safety, 20(2), 115-120. doi:10.1136/bmjqs.2008.029876

Soar, J., Nolan, J. P., Böttiger, B. W., Perkins, G. D., Lott, C., Carli, P., . . Nikolaou, N. I. (2015). European resuscitation council guidelines for resuscitation 2015. section 3. adult advanced life support. Resuscitation, 95, 100-147. doi:10.1016/j.resuscitation.2015.07.016

Tirkkonen, J., Tamminen, T., \& Skrifvars, M. B. (2017). Outcome of adult patients attended by rapid response teams: A systematic review of the literature. Resuscitation, 112, 43-52. doi:10.1016/j.resuscitation.2016.12.023 
Tirkkonen, J., Nurmi, J., Olkkola, K. T., Tenhunen, J., \& Hoppu, S. (2014). Cardiac arrest teams and medical emergency teams in finland: A nationwide cross-sectional postal survey. Acta Anaesthesiologica Scandinavica, 58(4), 420-427. doi:10.1111/aas.12280

Topple, M., Ryan, B., Baldwin, I., McKay, R., Blythe, D., Rogan, J., . . Shea, A. (2016a). Tasks completed by nursing members of a teaching hospital medical emergency team. Intensive and Critical Care Nursing, 32, 12-19. doi:10.1016/j.iccn.2015.08.008

Topple, M., Ryan, B., McKay, R., Blythe, D., Rogan, J., Baldwin, I., \& Jones, D. (2016b). Features of an intensive care based medical emergency team nurse training program in a university teaching hospital. Australian Critical Care, 29(1), 46-49. doi:10.1016/j.aucc.2015.03.001

Wallin, C., Meurling, L., Hedman, L., Hedegård, J., \& Felländer-Tsai, L. (2007). Target-focused medical emergency team training using a human patient simulator: Effects on behaviour and attitude. Medical Education, 41(2), 173-180.

Warren, J. N., Luctkar-Flude, M., Godfrey, C., \& Lukewich, J. (2016). A systematic review of the effectiveness of simulation-based education on satisfaction and learning outcomes in nurse practitioner programs. Nurse Education Today, 46, 99-108. doi:10.1016/j.nedt.2016.08.023

White, K., Scott, I. A., Vaux, A., \& Sullivan, C. M. (2015). Rapid response teams in adult hospitals: Time for another look? Internal Medicine Journal, 45(12), 1211-1220. doi:10.1111/imj.12845

Winters, B.,D., \& DeVita M., A., (2011). Rapid Response Systems History and Terminology. M.A. DeVita, K. Hillman and R. Bellomo (Eds.), In Textbook of Rapid Response Systems: Concept and Implementation (pp 3-8). New York; Springer. DOI: 10.1007/978-0-387-92853-1 Accessed 30.3.17. Retrieved from https://books.google.fi/books?id=fRnDLh_jdwUC\&printsec $=$ frontcover\#v $=$ onepage \&q\&f=fals $\underline{\mathrm{e}}$ 